\title{
WHEN DOES THE MOORE-PENROSE INVERSE FLIP?
}

\author{
R. E. HARTwig AND P. PATRÍCIO
}

Abstract. In this paper, we give necessary and sufficient conditions for the matrix $\left[\begin{array}{ll}a & 0 \\ b & d\end{array}\right]$, over a *-regular ring, to have a Moore-Penrose inverse of four different types, corresponding to the four cases where the zero element can stand. In particular, we study the case where the MoorePenrose inverse of the matrix flips.

Mathematics subject classification (2010): 15A09, 16E50, 16W10.

Keywords and phrases: rings, triangular matrices, von Neumann regularity, Moore-Penrose inverse.

\section{REFERENCES}

[1] A. Ben Israel and T. N. E. Greville, Generalized Inverses, Theory and Applications, 2nd Edition, Springer, New York 2003.

[2] S. K. BERBERIAN, Baer rings and Baer *-rings, available www.ma.utexas.edu/mp_arc/c/03/ 03-181.pdf

[3] R. Cline, Representations for the generalized inverse of a partitioned matrix, J. Soc. Indust. Appl. Math. 12 (1964), 588-600.

[4] R. CLINE, Representations for the generalized inverse of sums of matrices, J. SIAM Numer. Anal Ser B 2, 1 (1965), 99-114.

[5] R. HARTwig, Block generalized inverses, Arch. Rational Mech. Anal. 61, 3 (1976), 197-251.

[6] R. HARTWIG AND P. PATRICIO, G-inverses and path products, in preparation.

[7] C.-H. Hung And T. L. Markham, The Moore-Penrose inverse of a partitioned matrix $M=\left(\begin{array}{ll}A & 0 \\ B\end{array}\right)$, Czechoslovak Mathematical Journal 25 (100), 3 (1975), 354-361.

[8] I. KAPlansky, Elementary divisors and modules, Trans. Amer. Math. Soc. 66 (1949), 464-491.

[9] I. KAPLANSKY, Any orthocomplemented complete modular lattice is a continuous geometry, Ann. of Math. (3) 61 (1955), 524-541.

[10] I. KAPLANSKY, Rings of operators, W. A. Benjamin, Inc., New York-Amsterdam, 1968.

[11] J. J. Koliha, D. DJoRdJEvić AND D. CVetKović, Moore-Penrose inverse in rings with involution, Linear Algebra Appl. 426, 2-3 (2007), 371-381.

[12] C. MeYER, Generalized inverses of block triangular matrices, SIAM J. Appl. Math. 19 (1970), 741 750.

[13] N. Prijatelu And I. VidaV, On special * -regular rings, Michigan Math. J. 18 (1971), 213-221. 